\title{
Genetic Algorithm Based Speed Control of PMDC Motor Using Low Cost PIC 16F877A Microcontroller
}

\author{
Thangavel Vijayakumar'1, Subramaniam Muthukrishnan', Gopalraj Murugananth ${ }^{2 *}$ \\ ${ }^{1}$ EEE Department, Sri Eshwar College of Engineering, Coimbatore, India \\ ${ }^{2}$ EEE Department, Ahalia School of Engineering and Technology, Palakkad, India \\ Email:vijaypoy@gmail.com, mutudt04@gmail.com, gmurugananth@gmail.com
}

Received 17 March 2016; accepted 20 April 2016; published 8 June 2016

Copyright @ 2016 by authors and Scientific Research Publishing Inc.

This work is licensed under the Creative Commons Attribution International License (CC BY). http://creativecommons.org/licenses/by/4.0/

c) (i) Open Access

\section{Abstract}

This paper mainly aims at proposing an effective method of speed control of the low power motors like Permanent Magnet Direct Current (PMDC) motor used in the orthopedic surgeries using a natural optimization technique called genetic algorithm. Using this method, better values of Performance parameters like rise time, settling time, fall time, peak overshoot and steady state are achieved compared to the conventional PI controller. The SIMUINK MODEL of both the controller operation is obtained using MATLAB version R2013a. The simulated results reveal that the proposed control drive exhibits reduced peak overshoot, rise time, settling time and steady state error. An experimental setup is devised to validate the simulation results. The comparative analysis made depicts the superiority of the proposed algorithm with reference to its conventional counterpart.

\section{Keywords}

Effective, PMDC, Orthopaedic, Optimization, Performance Indices, Rise Time, Fall Time, Peak Overshoot, Steady State Error, PI, MATLAB

\section{Introduction}

DC motors are in general much more adaptable to adjustable speed drives than ac motors which are associated with a constant speed rotating fields. Indeed this susceptibility of dc motors to adjustment of their operating speed over wide ranges and by a variety of methods is one of the important reasons for strong competitive posi-

${ }^{*}$ Corresponding author.

How to cite this paper: Vijayakumar, T., Muthukrishnan, S. and Murugananth, G. (2016) Genetic Algorithm Based Speed Control of PMDC Motor Using Low Cost PIC 16F877A Microcontroller. Circuits and Systems, 7, 1334-1340.

http://dx.doi.org/10.4236/cs.2016.78116 
tion of dc motors in modern industrial drives. There are different methods of speed control strategies and controllers for the dc motor. The DC drive system consists of a chopper circuit for the control of input voltage to the armature. The speed of the DC motor in turn is decided by the armature input voltage [1]-[4]. These controllers include both the conventional controllers like PI (Proportional Integral) and different modern intelligent controllers. The tuning of the PI, PID or PD controller employed in this drive for efficient operation is assisted with the help of Ziegler-Nichol's method [5]. Self-tuning of the PID controllers is addressed in [6], whereas the adaptive tuning method for HVAC system is defied in [7].

A PI controller to minimize the speed error of servo motor has been focused [8]. Several comparative analyses of P, PI and PID controllers with their modern counterparts have been studied [9]-[12]. A Fuzzy logic based DC motor drive has been suggested for accurate drilling which uses current control method [13]. The performance of anti-windup PI controller tuned using fuzzy logic was designed, developed and analyzed experimentally [14]. However, in all the aforementioned speed control techniques, tuning of P, PI and/or PID controllers that have been addressed doesn't provide good and efficient performance. To enhance the system performance in steady state and transient state conditions, this paper proposes, a Genetic Algorithm (GA) based tuning of PI controller for chopper driven PMDC motor. The proposed system has been simulated using Matlab/Simulink and experimentally validated.

\section{Modelling of the PMDC Motor}

The PMDC motors are the low power motors that are used in the medical treatment for orthopaedic surgical simulators which requires less input power and its operation is quite and better for this application. The speed of the motor can be controlled by varying the armature voltage. The following is the basic armature voltage equation of the PMDC motor. The mathematical model of the PMDC motor is as given by Equation (1) [15] [16]. From the above authors analysis the following mathematical model of the motor is derived from the equivalent circuit as shown in Figure 1.

$$
V a=E+I a * R a+\left(L a * \frac{\mathrm{d} I a}{\mathrm{~d} t}\right)
$$

where $V a$ is the armature voltage in Volts,

$I a$ is the armature current in $A$,

$L a$ is the armature inductance in $H$,

$E$ is the back emf in Volts.

The following figure shows the Simulink block diagram of a PMDC motor.

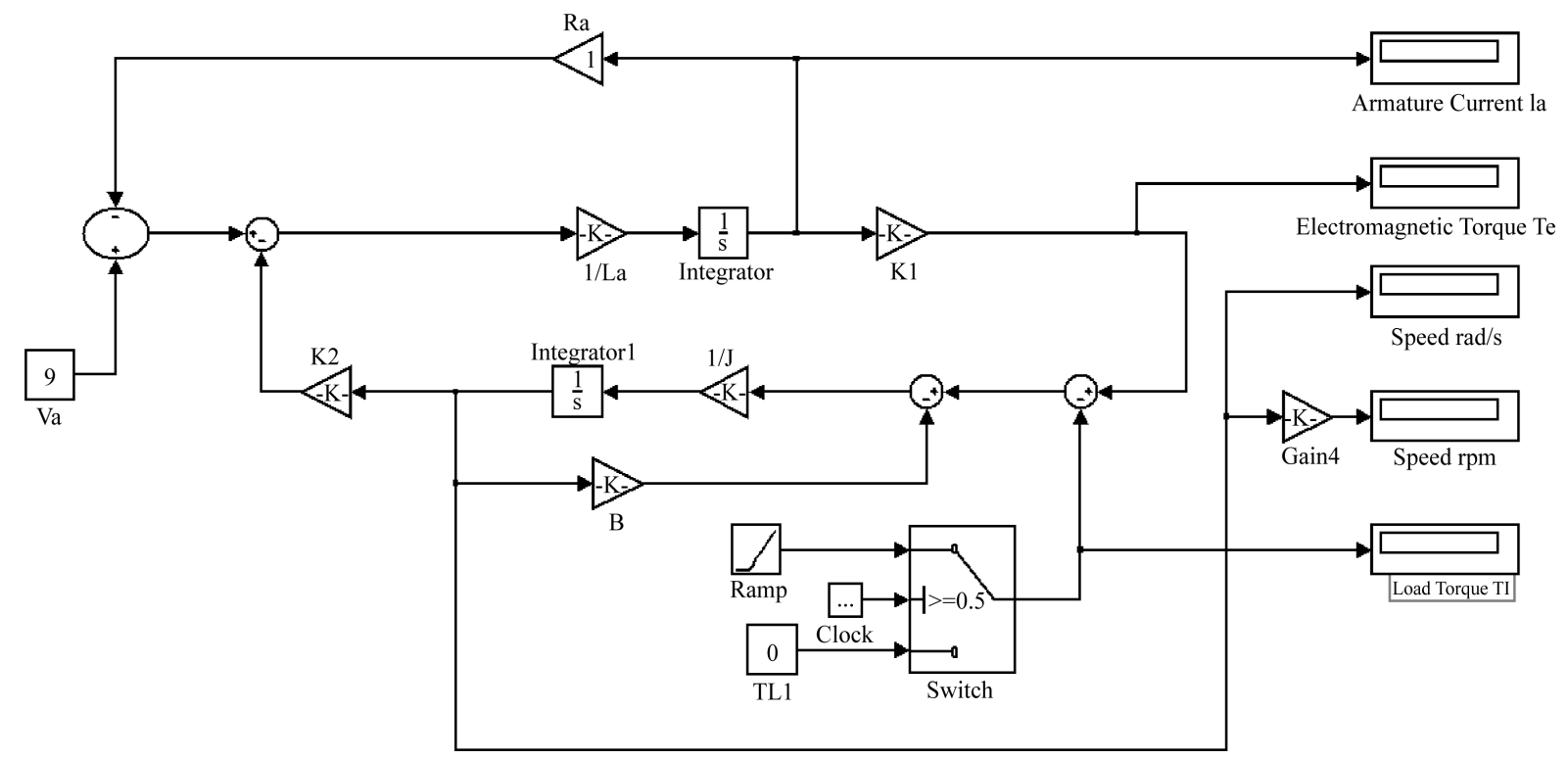


The various advantages of PMDC motors are

- Higher efficiency since no loss in field circuit

- Linear torque speed characteristics

- Higher magnetic flux density in air gap and so better dynamic performance

- Compact size

- Simplified construction

- Free from maintenance

- Wide operating speed range

- Ability to adapt a range of power sources.

\section{PI Controller Based PMDC Motor}

The PI controller calculation (algorithm) involves two separate parameters, and is accordingly the proportional, and the integral values, denoted P, I. The proportional value determines the reaction to the current error, the integral value determines the reaction based on the sum of recent errors, and the derivative value determines the reaction based on the rate at which the error has been changing.

The weighted sum of these three actions is used to adjust the process via a control element such as the position of a control valve or the power supply of a heating element. Heuristically, these values can be interpreted in terms of time: P depends on the present error, I on the accumulation of past errors. By tuning the two constants in the PI controller algorithm, the controller can provide control action designed for specific process requirements.

The response of the controller can be described in terms of the responsiveness of the controller to an error, the degree to which the controller overshoots the set point and the degree of system oscillation. It is to be noted that the use of the PI algorithm for control does not guarantee optimal control of the system or system stability. Figure 2 shows the block diagram for the speed control of PMDC motor.

Figure 3 shows the Simulink output obtained for the PMDC motor control using PI controller.

\section{GA optimized Controller for PMDC Motor}

In order to achieve an effective control of PMDC motor, the GA optimization technique is used to tune the parameters of the PI controller. Genetic algorithm is a biological inspired algorithm used [17] [18]. It helps in optimizing the various gain functions of PI controllers. The Simulink response of the GA tuned PI controller for a set speed of 500 RPM has been depicted in Figure 4.

The various genetic parameters used are given in Table 1.

\section{Experimental Setup of Chopper Controller Drive}

An experimental setup has been designed and the hardware has been realized using a Peripheral Interface Controller (PIC) microcontroller. The block diagram and circuit of the hardware is shown in Figure 5 \& Figure 6. It comprises of a PIC 16F877A microcontroller, which has an inbuilt PWM generator and an Analog to Digital Converter (ADC) unit. The MOSFET IRF840 is used as the switching device. The variations in the pulse width

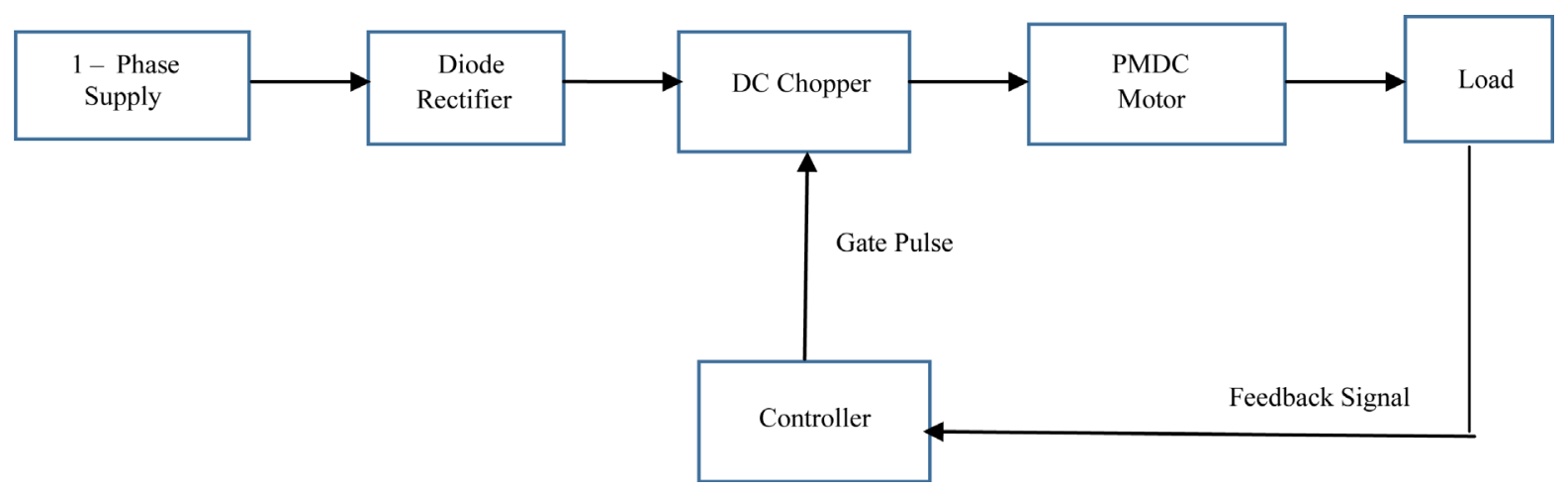




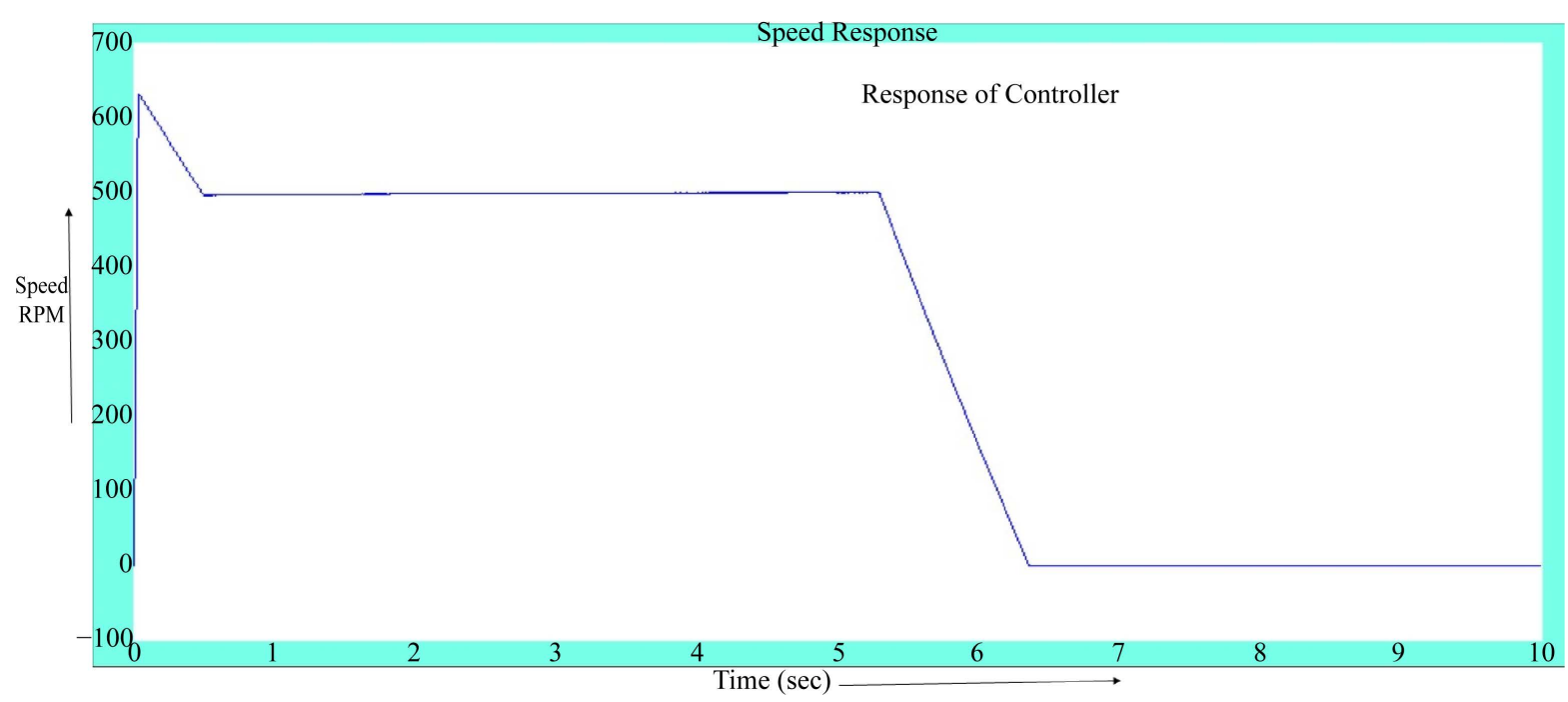

Figure 3. Response of PI controlled PMDC motor for 500 RPM.

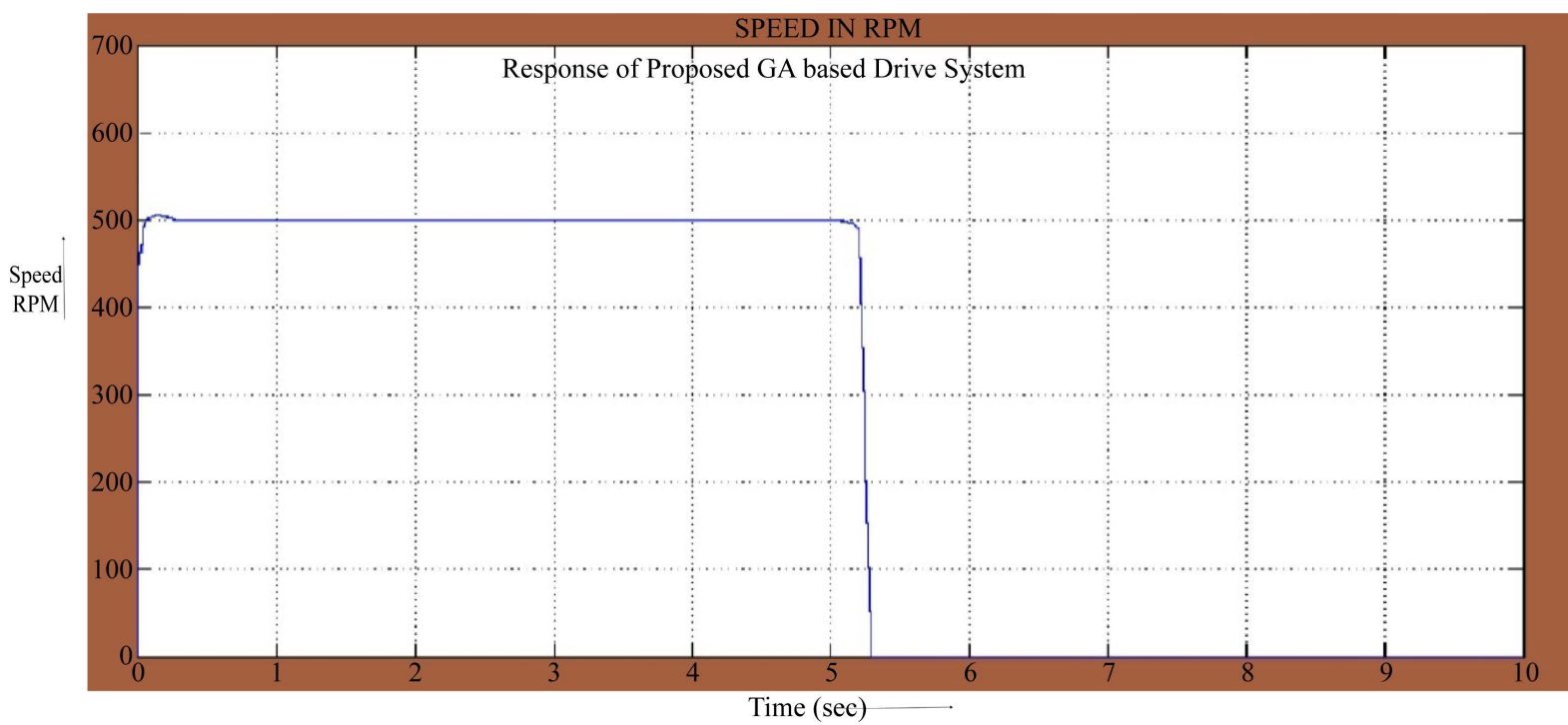

Figure 4. Response of GA Tuned PI controller for set speed of 500 RPM.

Table 1. Genetic parameters.

\begin{tabular}{cc}
\hline PARAMETER & VALUE/METHOD \\
\hline Population size & 21 \\
Number of iterations & 7 \\
Fitness function & $Y=(y+7) \times 255 / 14$ \\
Selection & Tournament selection \\
Cross over probability & 0.5 \\
Mutation probability & 0.01 \\
\hline
\end{tabular}

have been observed for the speed values of $500 \mathrm{rpm}$ and $1500 \mathrm{rpm}$. The experimental results are portrayed in Figure 7 and Figure 8 for the speed values of 500 and $1500 \mathrm{rpm}$ respectively.

\section{Results and Discussions}

Table 2 elucidates the comparative analysis of simulated results of conventional PI controller and the proposed 


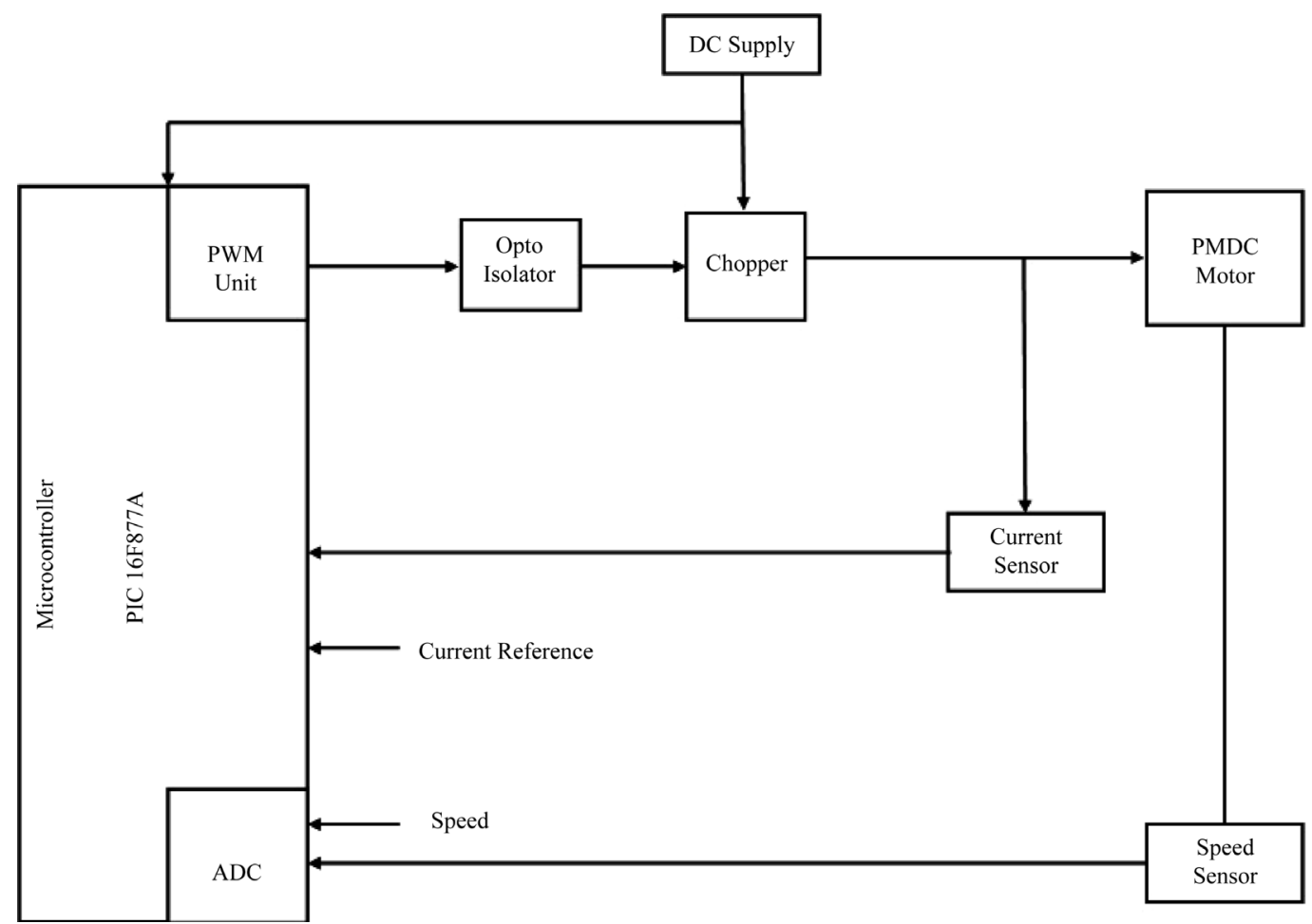

Figure 5. Block diagram of hardware.

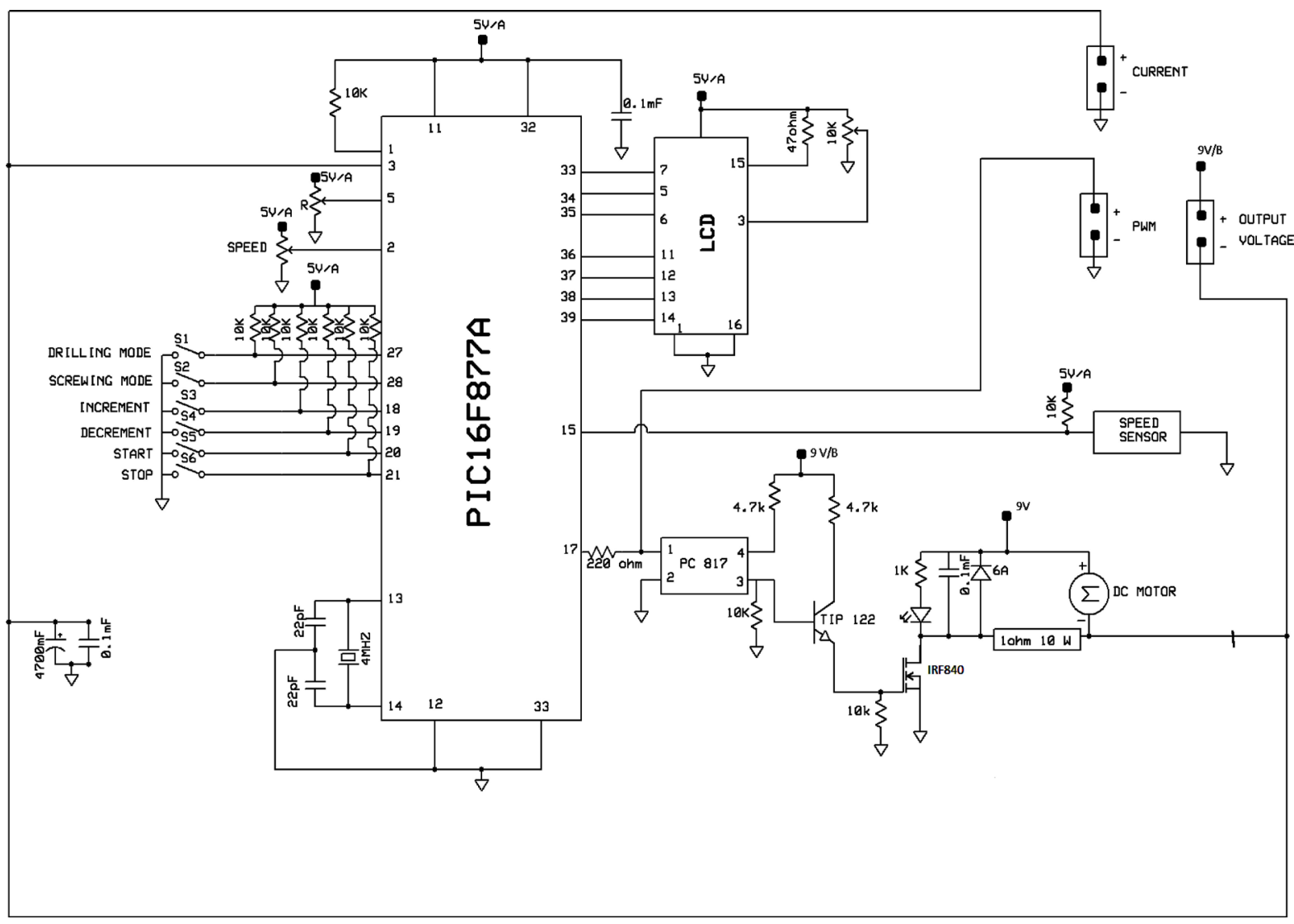

Figure 6. Circuit diagram of chopper controlled drive using PIC. 


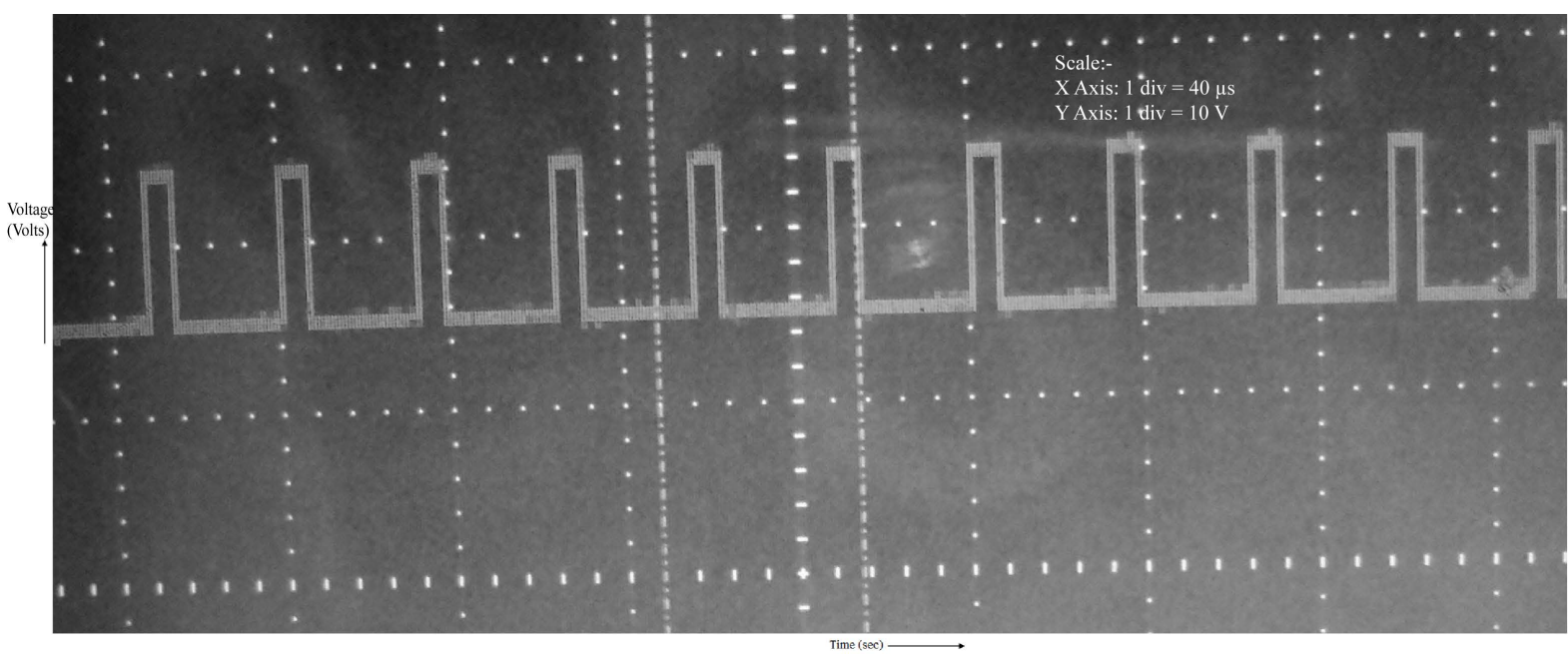

Figure 7. PWM pulse generated for $500 \mathrm{rpm}$.

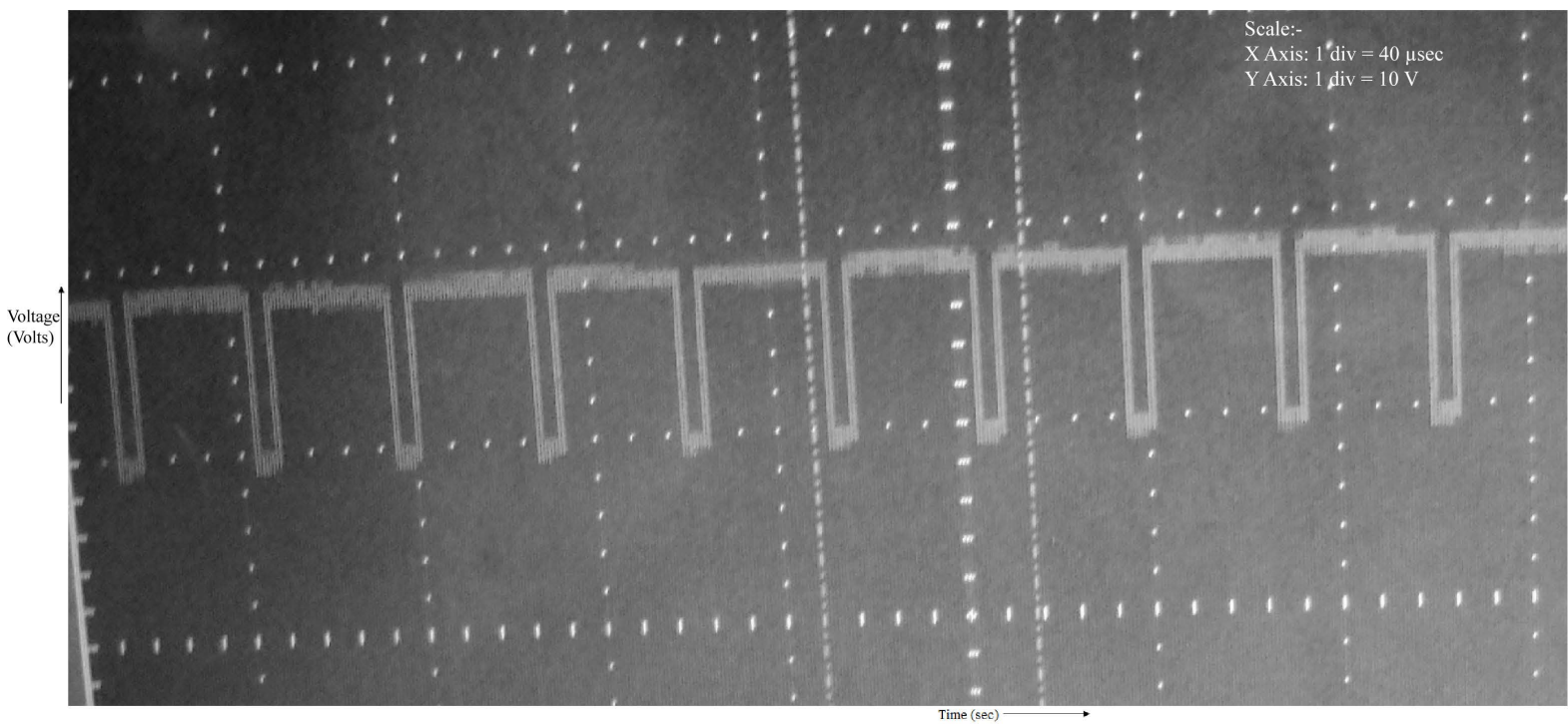

Figure 8. PWM pulses generated for $1500 \mathrm{rpm}$.

Table 2. Comparative analysis of proposed and conventional drive system.

\begin{tabular}{|c|c|c|c|c|c|c|c|c|c|c|}
\hline \multirow{2}{*}{$\begin{array}{l}\text { Set Speed } \\
\text { in RPM }\end{array}$} & \multicolumn{2}{|c|}{$\begin{array}{l}\text { Maximum Peak } \\
\text { Overshoot in \% }\end{array}$} & \multicolumn{2}{|c|}{$\begin{array}{l}\text { Rise time } \\
\text { in seconds }\end{array}$} & \multicolumn{2}{|c|}{$\begin{array}{l}\text { Settling time } \\
\text { in seconds }\end{array}$} & \multicolumn{2}{|c|}{$\begin{array}{l}\text { Fall time } \\
\text { in seconds }\end{array}$} & \multicolumn{2}{|c|}{$\begin{array}{l}\text { Steady state } \\
\text { error in \% }\end{array}$} \\
\hline & GA & PI & GA & PI & GA & PI & GA & PI & GA & PI \\
\hline 500 & 0.2 & 26.2 & 0.01 & 0.028 & 0.3 & 4.68 & 0.15 & 1.063 & 0 & 0.5 \\
\hline 1000 & 1 & 9.4 & 0.01 & 0.0395 & 0.2 & 2.732 & 0.05 & 2 & 0 & 0.595 \\
\hline 1200 & 1 & 7.08 & 0 & 0.048 & 0.2 & 3.14 & 0.2 & 2.304 & 0 & 0.66 \\
\hline 1500 & 1.33 & 4.7 & 0 & 0.0773 & 0.2 & 3.5 & 0.1 & 2.8 & 0.12 & 0.71 \\
\hline
\end{tabular}

Genetic Algorithm based chopper drive circuit. For a low speed of $500 \mathrm{rpm}$, the proposed system resulted in less peak overshoot of $0.2 \%$ whereas the conventional system offered $26.2 \%$. Similar results were found for medium and high speed values. For instance, at $1000 \mathrm{rpm}$, the peak overshoot was $1 \%$ in proposed system and $1.33 \%$ for $1500 \mathrm{rpm}$. These values are very low compared to the conventional system which offered $9.4 \%$ and $4.7 \%$ for 1000 and 1500 set rpm values.

The other control system parameter which is taken up for study is steady state error. The steady state error of 
conventional system is $0.5 \%$ at $500 \mathrm{rpm}$ and $0.71 \%$ at $1500 \mathrm{rpm}$. For these two set speed values, the proposed drive systems offered very low and even zero steady state error. For 500, 1000 and 1200 rpm, the steady state error of the proposed system is zero whereas for the high speed of $1500 \mathrm{rpm}$, it offered $0.12 \%$. Alike results have been portrayed for the other parameters viz. rise time, settling time and fall time. All these results infer the superiority of the proposed genetic algorithm based chopper drive for PMDC motors.

\section{Conclusion}

Thus it can be concluded that the proposed controller using GA optimization helps in achieving an effective control for the PMDC motor when compared to the conventional PI controller. Also from the tables in Section 4 and 5 , it is clear that the performance parameters of the motor operation like settling time, rise time, fall time and peak overshoot are better and there is no steady state error in case of the proposed intelligent controller. The experimental results validate the simulation results.

\section{References}

[1] Jaafer, J.S. and Mahdi, M.C. (2013) Speed Control of Separately Excited DC Motor Using Chopper. Journal of Kerbala University, 11, 26-35.

[2] Afrasiabi, N. and Yazdi, M.H. (2013) Dc Motor Control Using Chopper. Global Journal of Science, Engineering and Technology, 2013, 67-73.

[3] Pal, N., Sadhu, P.K. and Swaroop, R. (2012) Closed Loop Speed Control of DC Motors Used in Rock Drilling and Mud Pump Application. Proceedings of the International Multi-Conference of Engineers and Computer Scientists (IMECS), 2, 1052-1054.

[4] Mishra, G.K., Pandey, A.K. and Maurya, A. (2014) Combined Armature and Field Speed Control of DC Motor for Efficiency Enhancement. SSRG International Journal of Electrical and Electronics Engineering (SSRG-IJEEE), 1, 34-39.

[5] Prakash, Ch.B. and Naik, R.S. (2014) Tuning of PID Controller by Ziegler-Nichols Algorithm for Position Control of DC Motor. International Journal of Innovative Science, Engineering \& Technology, 1, 379-382.

[6] Mansoor, A.-K.Z. and Salih, T.A. (2013) Speed Control of Separately Excited D.C. Motor Using Self-Tuned Parameters of PID Controller. Tikrit Journal of Engineering Sciences, 20, 1-9.

[7] Bai, J.B. and Zhang, X.S. (2007) A New Adaptive PI Controller and Its Application in HVAC Systems. Energy Conversion and Management, 48, 1043-1054. http://dx.doi.org/10.1016/i.enconman.2006.10.023

[8] Singh, S. and Dipraj, A.K.P. (2012) Design of PI Controller to Minimize the Speed Error of D.C. Servo Motor. International Journal of Scientific \& Technology Research, 1, 95-98.

[9] Rao, K.S. and Mishra, R. (2014) Comparative Study of P, PI and PID Controller for Speed Control of VSI-Fed Induction Motor. International Journal of Engineering Development and Research (IJEDR), 2, 2740-2744.

[10] Adhikari, N.P., Choubey, M. and Singh, R. (2012) Dc Motor Control Using Ziegler Nichols and Genetic Algorithm Technique. International Journal of Electrical, Electronics and Computer Engineering, 1, 33-36.

[11] Mahdi, S.A. (2014) Optimization of PID Controller Parameters Based on Genetic Algorithm for Non-Linear Electromechanical Actuator. International Journal of Computer Applications, 94, 11-20.

[12] Murugananth, G., Vijayan, S. and Muthukrishnan, S. (2012) Analysis of Closed Loop Chopper Controlled Drive for PMDC Motors Using PID Controller. IOSR Journal of Electrical and Electronics Engineering (IOSRJEEE), 2, 32-34.

[13] Murugananth, G. and Vijayan, S. (2012) Development of Closed Loop Chopper Controlled Drive for PMDC Motors Used in Orthopedic Surgical Simulators. International Journal of Computer Science and Technology, 3, 872-874.

[14] Murugananth, G., Samidurai, K., Muthukrishnan, S. and Vijayan, S. (2015) Experimental Validation of Fuzzy-Tuned AWPI Controller-Based Chopper Driven PMDC Motor. Journal of Testing and Evaluation, 43, 1-12. http://dx.doi.org/10.1520/JTE20130284

[15] Sankar, R. and Ramareddy, S. (2011) A Novel Control Strategy Using Neuro-Fuzzy Controller for PMDC Drive. European Journal of Scientific Research, 54, 29-45.

[16] Chandrasekaran, N. and Thiyagarajah, K. (2011) Modeling and MATLAB Simulation of Pumping System Using PMDC Motor Powered by Solar System.

[17] Malhotra, R., Singh, N. and Singh, Y. (2011) Genetic Algorithms: Concepts, Design for Optimization of Process Controllers. Computer and Information Science, 4, 39-54.

[18] Sivanandamand, S.N. and Deepa, S.N. (2008) Introduction to Genetic Algorithm. Springer-Verlag, Berlin, Heidelberg. 